\title{
北京市外来人口集聚型城中村流动人口 职住分离研究
}

\author{
郑承智 ${ }^{1}$, 张旺锋 ${ }^{*}$, 武炳炎 ${ }^{1}$, 梁 博 ${ }^{2}$ \\ (1. 兰州大学资源与环境学院,兰州 730000; 2. 北京师范大学减灾与应急管理研究院,北京 100875)
}

\begin{abstract}
摘 要: 居住和就业是居民日常生活的主要内容, 随着中国城市化进程加快, 城市中低收人群体的职住分离现象正 得到越来越多的关注。本文采用人口集聚指数、GIS 空间分析及Logit回归分析等方法,利用北京市“六普”及实地 调研数据, 来获取外来人口集聚型城中村流动人口通勤及职住特征, 并对影响因素进行分析。结果表明: (1)北京流 动人口集中于城市拓展区, 呈 “环状圈层”分布特征。(2)近郊城中村流动人口通勤距离普遍较长, 职住分离较明显, 相应通勤时间也较长; 远郊城中村流动人口通勤距离较短, 以就地工作为主, 由于远离城市核心区, 公共服务设施 的可达性较差。(3)家庭就业人数、未成年及老人数、住京时长、收人、受教育程度、行业、交通工具选择等对其通勤 距离具有显著影响。上述结论可为研究城市弱势群体工作居住空间结构、制定城市规划等提供参考。

关 键 词: 通勤;流动人口; 职住分离; 城中村; 北京
\end{abstract}

\section{1 引言}

2010 年以来, 北京市常住人口规模进人较为稳 定的增长时期,而流动人口增速整体快于常住人 口。2015 年, 北京市流动人口规模达到 823 万人, 较 2010 年的 705 万人净增 118 万人。近几年, 北京 市正在疏解非首都功能,大批劳动密集型企业将整 体迁出北京。同时城中村治理力度也将进一步加 大, 流动人口生活空间可能被压缩。面对这样的形 势, 北京市城中村流动人口的通勤职住情况及其影 响因素,值得深入探究。

空间错位理论本质是城市居民居住和就业的 空间不均衡。通勤正是该理论的主要内容, 即居民 就业地和居住地分离而产生的出行行为, 它直接反 映了城市内部居住和就业的空间关系, 是解读城市 空间结构的重要视角(张艳等, 2013), 也是城市地 理、城市规划、城市交通等学科研究的热点问题 (Horner, 2004)。目前, 国外已有大量关于通勤模式
(Sohn, 2005)、职住关系与通勤行为(Giuliano, 1991; Peng, 1997; Levine,1998; Lee et al, 2003)、城市空间 与通勤行为 (Shen, 2000; Aguilera, 2005)等方面的研 究。国内学者对北京、广州、上海等大城市的居民 通勤格局和行为亦有较为深人的研究, 且大多数基 于调查数据，围绕通勤空间、通勤时间、通勤距离等 影响因素展开。例如, 周素红等(2006)利用 GIS 对 微观行为及空间感知的宏观空间模拟,应用于广州 的典型街区; 英成龙等(2016)借助职住分离指数法 分析了乌鲁木齐市辖区的职住空间匹配状况, 并得 到职住空间分离是其城市空间结构的突出特征; 孙 斌栋等(2015)利用Logit模型检验了街道尺度城市 建成环境对于居民通勤方式选择的影响,得出通过 优化土地利用规划来优化居民通勤结构的结论; 刘 志林等(2011)以北京市为例, 以职住距离作为研究 职住分离程度的主要测度指标, 描述了北京职住分 离现象及其特征;张艳等(2013)描述北京城市居民 通勤行为的一般特征, 比较城市内部不同居住地域

收稿日期: 2016-09;修订日期: 2016-11。

基金项目: 国家基础科学人才培养基金项目(J1210065) [Foundation: National Basic Scientific Personnel Training Foundation of China, No.J1210065]。

作者简介:郑承智(1989-), 男, 福建南平人,硕士生, 研究方向为城乡与区域规划和人口地理,E-mail: 951065465@qq.com。 通讯作者: 张旺锋(1968-), 男, 甘肃庆阳人,副教授, 研究方向为城市与区域规划和土地利用规划,E-mail: 454294705@qq.com。 
之间居民通勤格局的差异性, 折射出北京市居住与 就业空间重构的微观过程; 党云晓等(2015)以北京 为例, 分析土地利用混合度对居民职住分离的影 响, 发现微观层面土地利用混合度的提升的确有利 于减轻个体的职住分离。

目前, 职住分离这一趋势对不同城市居民产生 不同程度的影响, 可能加剧城市低收入群体的弱势 地位,造成更多的社会问题和城市空间问题(王宁 等, 2009; 刘志林等, 2010)。李小广等(2013)针对重 庆市公共租赁房居民实证研究, 发现公共租赁房空 间布局导致中低收人人群通勤距离和时间都变长; 孟斌等(2012)以北京郊区 2 个大型居住区一一望京 和天通苑居住区为研究对象, 发现通勤时间较长是 近郊大型居住区居民的共性; 宋金平等(2007)认为, 随着住宅郊区化的大规模发展, 北京出现居住和就 业的空间错位问题, 造成低收人阶层通勤的时间成 本与经济成本增加, 导致交通拥堵、社会隔离等问 题; 贾晓朋等(2015)对北京市不同类型居住区居民 进行通勤行为分析, 发现不同社区居民通勤存在显 著差异, 体现了城市极化现象的不同层面特征; 孙 斌栋等(2008)对上海进行实证分析, 结果显示, 上海 的就业一居住空间均衡性趋于减弱, 在城市交通层 面上跨区交通出行增加, 平均出行时间和距离上 升。而针对城中村流动人口通勤行为研究则较少 (徐市融等, 2010), 以往研究重点放在城中村成因、 分类、非正规经济及改造等方面(李钊, 2001; 李晴 等, 2002; 张京祥等, 2007; 陶海燕等, 2014), 微观研 究着重于流动人口日常生活、家庭模式、住房状况、 社会融合现状与测度以及流动人口身份认同等方 面(兰宗敏等, 2010, 2012; 卢小君等, 2012; 余运江 等, 2012; 杨菊华等, 2013; 汪明峰, 2015)。由此可 见, 对城中村居民的职住分离和出行轨迹研究, 对 理解城市弱势群体的工作生活空间结构, 城市特殊 空间形态形成、城市社会关系组织及演化都有重要 意义, 有助于从宏观角度分析城市问题产生的根 源, 从全域追求职住平衡, 为城市用地空间布局的 调整、城市空间职能的转换、疏解非首都职能等提 供理论指导。鉴于通勤在城市空间结构的重要性 以及城中村流动人口职住分离方面研究的不足, 本 文从城中村流动人口居住与就业地的空间关系角 度出发, 研究北京市以流动人口为主体的城中村通 勤状况, 以反映居住一就业空间匹配问题, 可为掌
握城市主要人群工作生活空间结构、制定城市规划 等提供一定参考。

\section{2 研究设计}

\section{1 研究区域选择}

本次调研区域为北京市流动人口较为密集的 城中村, 而本文将“城中村”定义为: 城市建成区内 土地性质为集体用地的区域。合理选定研究区将 最大程度表明调研对象的代表性。据此本文利用 北京市 “六普”分街道数据, 共涉及 306 个乡、镇、街 道单元,采用集聚指数(罗仁朝等, 2008)来衡量北京 市各地区流动人口集聚情况。同时认定数据结果 呈现的外来人口集中区即代表当前流动人口聚 集区。

集聚指数衡量过程: 将流动人口的空间密度以 及占区域总人口的比例作为 2 个基本指标, 然后对 2 个指标进行无量纲标准化处理(如下):

密度指数: $I d_{i}=D f_{i} / \operatorname{Avg}\left(D f_{i}\right) \quad(i=1,2, \cdots, n)$

比重指数: $I r_{i}=R f_{i} / \operatorname{Avg}\left(R f_{i}\right) \quad(i=1,2, \cdots, n)$ 式中: $D f_{i}$ 为统计单元 $i$ 的流动人口密度; $A v g\left(D f_{i}\right)$ 为 区域流动人口密度均值; $R f_{i}$ 为统计单元流动人口占 比; $A v g\left(R f_{i}\right)$ 为区域流动人口占比均值。在此基础 上, 对标准化处理后的指数进行划定: $I d_{i} 、 I r_{i}$ 同时 $\geqslant 1$ 时, 即密度指数与比重指数均高于均值的统计区, 划分为流动人口高密度聚集区。当 $I d_{i} \geqslant 1, I r_{i}<1$, 且 $I d_{i}+I r_{i} \geqslant 2$ 时, 为中密度聚集区 $\mathrm{I}$ 类; 当 $I d_{i}<1, I r_{i} \geqslant 1$, 且 $I d_{i}+I r_{i} \geqslant 2$ 时, 为中密度聚集区 II 类。其他则为流 动人口低密度聚集区。经 ArcGIS 可视化及空间分 析可得, 北京市流动人口高、中、低度区叠加后的地 理学特征显著, 为“环状圈层”格局。

根据以上结果, 本文调研采样点选择中高密度 聚集区内的城中村, 主要分布在朝阳、丰台、海淀等 地,并选取其中 14 个城中村(图 1)。

\section{2 调研对象选择及数据来源}

本次调研对象选择需满足以下 2 个条件:一是 以居住在中高密度聚集区内城中村流动人口 ${ }^{\mathbb{1}}$ 为研 究对象; 二是选择该群体中年龄在 18 50 岁之间, 且 可独立辨别问卷内容的流动人口。当前, 调研对象 整体规模较大, 其文化水平和身份也相对混杂, 对 该类型流动人口进行研究分析, 具有一定的社会和 实践意义。 


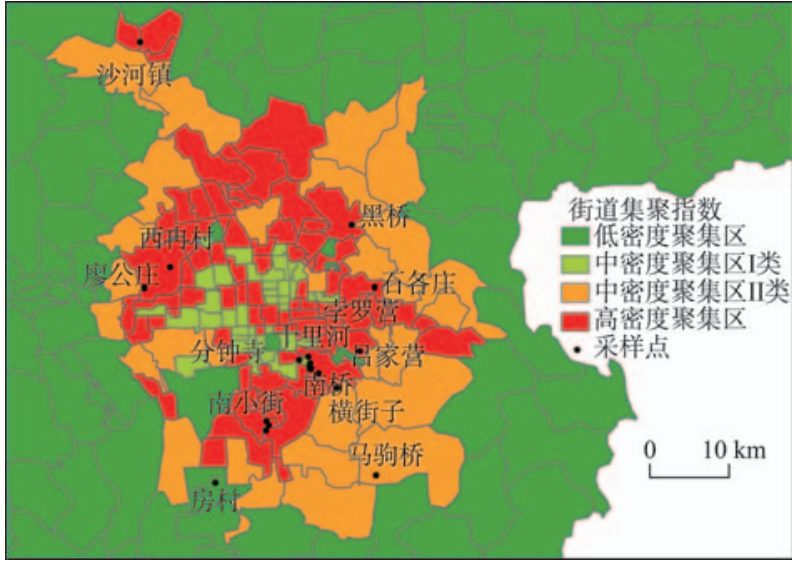

图 1 北京市流动人口空间分布及调查研究对象分布

Fig.1 Spatial distribution of floating population in Beijing and the location of the survey areas

为了研究北京城中村流动人口通勤情况及影 响因素,2015 年 10-12月期间,对选定的城中村进行 问卷调研,采用重点城中村抽样方法。通过与被访 者面对面调研,共发放问卷 1050 份, 收回问卷 817 份, 根据研究目的, 剔除数据存在缺失的问卷, 整理 出有效问卷 625 份, 有效问卷率 $76.5 \%$ 。此次调查 内容除样本群体的人口、经济、社会等信息外,还包 含本文所需的相关职住信息(居住地、工作地、交通 方式等)。

\section{3 研究方法}

通勤距离测算方法 ${ }^{2}$ : 利用 GIS 空间和属性分 析功能, 将每个样本点的职住进行空间定位, 然后 在 GIS 中逐一进行采样及属性数据录人, 生成可处 理的城中村流动人口工作和居住地的点、线图层数 据,通过属性计算及图形轨迹可视化分析, 得到不 同城中村流动人员通勤距离以及相应的空间分布 特征。

本文利用调查城中村流动人口的通勤空间、通 勤距离与通勤时间特征数据结果, 综合反映城中村 流动人口的职住匹配现状; 同时运用Logit 回归模 型分析不同城中村流动人口经济社会特征以及城 中村居住环境是否对通勤距离产生影响。

\section{3 结果与分析}

\section{1 城中村流动人口社会经济特征}

此次调研社会经济特征涉及被访者的性别、婚 姻状况、户籍、文化程度、年龄、月收人、家庭就业人
数、未成年人及老年人数、家庭规模、来京时间、工 作行业、就业次数、交通工具等(表 1$)$ 。

(1) 个人属性特征。男性居多 $(63.68 \%)$, 且大多 数为中青年; 受教育水平以初高中和大专/本科为 主; $73.60 \%$ 的城中村流动月人口收人在 2000 6000 元之间, 高于 6000 元的群体占到 $20.64 \%$, 群体整体 收人水平较低, 为城市中低收人弱势群体; 年龄在 20 30 岁与 31 40 岁的比例分别为 $60.80 \%$ 和 $25.60 \%$ 。

(2) 家庭情况。家庭就业人数为 1 人的占全部 样本的 $30.88 \%$, 就业人数为 2 人的占 $59.68 \%$, 表明 城中村流动人口从业人员基本以个人或者夫妇形 式为主; 有 1 个及以上未成年人/老年人家庭占 $41.76 \%$, 另外有 $79.36 \%$ 的家庭至少携带 1 个直系亲 属, 与近几年流动人口家庭化趋势研究相符。

(3) 就业情况。城中村流动人口在京居住时 间: 10 年以下共占 $89.28 \%$, 其中 3 年及以下占 $45.12 \%, 3 \sim 5$ 年占 $20.96 \%, 5 \sim 10$ 年占 $23.20 \%$; 在京 更换工作频率 1 2 次的占比达到 $72.96 \%$, 表明北京 城中村流动人口的多样性及相对稳定性; 被访者从 事行业主要有批发零售、住宿餐饮、居民服务等。

(4) 社会经济空间分布特征。城中村流动人口 中已婚人群通勤距离较短, 他们更倾向于在居住地 周围工作; 年龄对城中村流动人口空间分布产生影 响, 其中 20 40岁的新生代群体整体通勤距离较长, 由于接受社会各种业态能力以及体能上的优势, 其 出行限制也较少, 工作更加分散和随意, 空间分布 上表现以远离居住地为主; 文化程度越高的群体, 通勤距离也增加, 他们从事工作的技术性较强, 自 由性较大, 其居住和工作地之间距离较远。另外, 经济收人出现两极化趋势, 即收人最低和最高群体 通勤距离较长: 收人低者往往从事体力劳动, 例如 维修、流动卖菜等远离居住地的工作, 而高收人者 工作相对集中在城市核心区,而居住则在近郊区。

总体而言,社会经济特征反映了城中村流动人 口年轻化、家庭化等特征。通常已婚、年龄小、学历 高、收人较高和较低的城中村流动人口, 其工作更 倾向于远离居住地。

\section{2 通勤空间和通勤距离关系变化特征}

(1) 城中村流动人口工作地空间分布较为集 中: 主要在三四环和四五环间,三环以内、五环以外 分布较少。通过对 625 份标注了城中村流动人口工

(2)通勤距离为流动人口居住地与工作地的直线距离。 
表 1 城中村流动人口经济社会基本特征

Tab.1 Social and economic characteristics of the surveyed urban village floating population

\begin{tabular}{|c|c|c|c|c|c|}
\hline 变量 & & 样本量 & 样本比例 $/ \%$ & 平均通勤距离/m & 平均通勤时间/min \\
\hline \multirow[t]{2}{*}{ 性别 } & 女性 & 227 & 36.32 & 4092 & 42.0 \\
\hline & 男性 & 398 & 63.68 & 4264 & 41.8 \\
\hline \multirow[t]{2}{*}{ 婚姻状况 } & 已婚 & 383 & 61.28 & 3470 & 40.3 \\
\hline & 未婚 & 242 & 38.72 & 5359 & 44.3 \\
\hline \multirow[t]{2}{*}{ 户籍 } & 城市 & 113 & 18.08 & 4846 & 44.1 \\
\hline & 农村 & 512 & 81.92 & 4059 & 41.4 \\
\hline \multirow[t]{5}{*}{ 文化程度 } & 小学以下 & 26 & 4.16 & 1311 & 38.8 \\
\hline & 初中 & 162 & 25.92 & 2549 & 38.7 \\
\hline & 高中 & 178 & 28.48 & 3142 & 39.7 \\
\hline & 大学专科/本科 & 256 & 40.96 & 6266 & 45.8 \\
\hline & 硕士及以上 & 3 & 0.48 & 5187 & 33.3 \\
\hline \multirow[t]{5}{*}{ 年龄/岁 } & $\leqslant 20$ & 20 & 3.20 & 1947 & 40.5 \\
\hline & (20 30] & 380 & 60.80 & 4825 & 42.8 \\
\hline & (31 40] & 160 & 25.60 & 3867 & 41.4 \\
\hline & $(41 \sim 50]$ & 60 & 9.60 & 2085 & 38.7 \\
\hline & $>50$ & 5 & 0.80 & 1903 & 30.0 \\
\hline \multirow[t]{5}{*}{ 月收人/元 } & $\leqslant 2000$ & 36 & 5.76 & 5483 & 44.4 \\
\hline & (2000 4000] & 222 & 35.52 & 2921 & 39.6 \\
\hline & (4000 6000] & 238 & 38.08 & 4755 & 42.7 \\
\hline & (6000 8000] & 77 & 12.32 & 4204 & 41.6 \\
\hline & $>8000$ & 52 & 8.32 & 6242 & 46.3 \\
\hline \multirow[t]{4}{*}{ 家庭就业人数 } & 1 & 193 & 30.88 & 4033 & 42.5 \\
\hline & 2 & 373 & 59.68 & 4247 & 41.3 \\
\hline & 3 & 36 & 5.76 & 4386 & 43.1 \\
\hline & 4 个以上 & 23 & 3.68 & 4596 & 43.9 \\
\hline \multirow{4}{*}{$\begin{array}{l}\text { 家庭未成年人及老人 } \\
\text { 人数 }\end{array}$} & 0 & 364 & 58.24 & 5071 & 43.3 \\
\hline & 1 & 164 & 26.24 & 3094 & 38.8 \\
\hline & 2 & 47 & 7.52 & 2565 & 40.6 \\
\hline & $\geqslant 3$ & 50 & 8.00 & 3049 & 42.6 \\
\hline \multirow[t]{4}{*}{ 家庭规模/人 } & 1 & 119 & 19.04 & 4471 & 43.1 \\
\hline & 2 & 237 & 37.92 & 5103 & 42.8 \\
\hline & 3 & 158 & 25.28 & 3423 & 40.6 \\
\hline & $\geqslant 4$ & 111 & 17.76 & 3096 & 40.5 \\
\hline \multirow[t]{5}{*}{ 来京时间/年 } & $\leqslant 1$ & 78 & 12.48 & 4421 & 42.1 \\
\hline & $(1 \sim 3]$ & 204 & 32.64 & 4380 & 40.9 \\
\hline & $(3 \sim 5]$ & 131 & 20.96 & 3601 & 40.9 \\
\hline & $(5 \sim 10]$ & 145 & 23.20 & 4027 & 43.0 \\
\hline & $>10$ & 67 & 10.72 & 4957 & 43.9 \\
\hline \multirow[t]{6}{*}{ 工作行业 } & 批发零售业 & 120 & 19.20 & 2981 & 39.9 \\
\hline & 住宿餐饮业 & 107 & 17.12 & 2370 & 36.4 \\
\hline & 交通运输业 & 40 & 6.40 & 4730 & 38.8 \\
\hline & 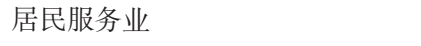 & 97 & 15.52 & 4687 & 44.5 \\
\hline & 信息传输、计算机服务业和软件业 & 71 & 11.36 & 7714 & 47.7 \\
\hline & 其他 & 190 & 30.40 & 4332 & 43.3 \\
\hline \multirow[t]{4}{*}{ 就业次数 } & 1 & 277 & 44.32 & 3993 & 40.5 \\
\hline & 2 & 179 & 28.64 & 4577 & 43.4 \\
\hline & {$[3 \sim 4]$} & 131 & 20.96 & 3694 & 42.4 \\
\hline & $>4$ & 38 & 6.08 & 5708 & 43.2 \\
\hline \multirow[t]{3}{*}{ 交通工具 } & 步行/自行车/电动车 & 299 & 47.84 & 2195 & 36.2 \\
\hline & 公交车/地铁 & 284 & 45.44 & 6266 & 47.6 \\
\hline & 私家车/出租车 & 42 & 6.72 & 4527 & 43.8 \\
\hline 总体 & & 625 & 100.00 & 4202 & 41.9 \\
\hline
\end{tabular}


作地点的有效问卷分析,得到北京市主城区 14 个城 中村的流动人口工作地点的空间分布(图 2)。城中 村流动人口工作地点主要集中在东城区、朝阳区、 海淀区、丰台区等 4 个地区。(1)工作地在三环内占 比 $18.23 \%$, 主要集中在国贸 SOHO、永安里、潘家 园、双井等地, 这些地方集中较多的商办楼及娱乐 设施,以从事金融、电子计算机、娱乐服务业为主, 三环其他地方工作则较为分散。(2)工作地在三四 环间占比 $36.94 \%$, 主要集中在十里河商区、吕家营 餐饮街以及城环城汽配城等地, 其他地方也有零散 分布, 上述三地主要以商贸服务、居民服务业为 主。其中, 十里河是北京市以家居建材为支柱的商 圈, 有众多家居建材行业, 包括居然之家、美联天 地、灯饰城及建材城等。吕家营餐饮街是北京主要 的热门商区, 据大众点评网数据表明, 分布其中的 餐饮项目达到 217 家, 调研中有 $7.36 \%$ 的被访者在 餐饮街工作。3工作地在四五环间占比 $31.94 \%$, 这 部分城中村流动人口工作集中程度较高, 且工作属 性较为同质, 主要分布在南小街村、亦庄工业区、孛 罗营汽修城和黑桥周围等地。其中, 南小街村流动 人口以从事服装制造为主, 亦庄工业园区城中村流 动人口主要为园区提供劳动力, 孛罗营地区城中村 流动人口主要从事汽修行业, 而黑桥地区城中村流 动人口则较多在 “798”从事文艺、商业服务以及电 子商务等; 由此可知, 以某个行业为主导的地区, 更 容易吸引属性一致的流动人口集聚。

(2) 城中村流动人口通勤直线距离集中在 3 $5 \mathrm{~km}$ 之间, 不同城中村通勤距离差异较大。基于 625 份有效问卷分析(表 2), 发现 14 个城中村流动人

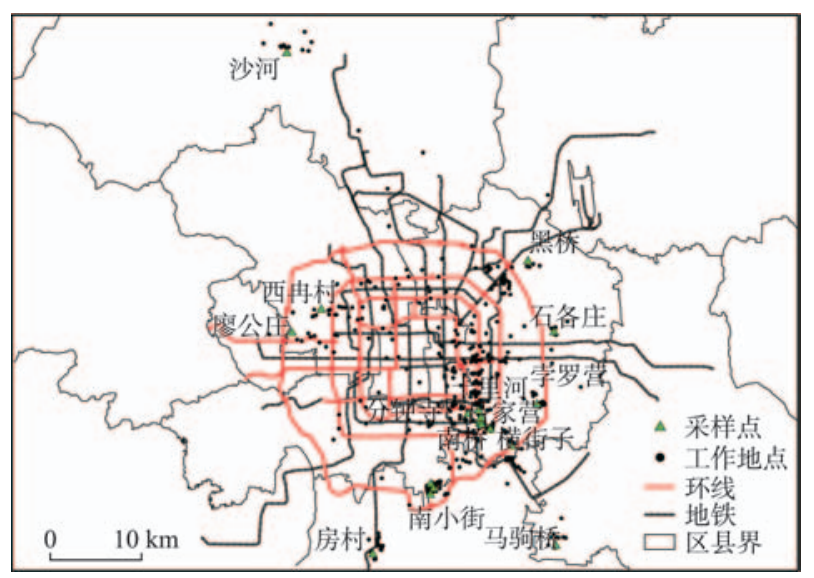

图 2 样本流动人口工作地点分布图

Fig.2 Workplace distribution of the surveyed floating population
口通勤距离集中分布在 3 5 km 之间( $81.6 \%$ 的人口 通勤距离在此范围内), 还有 $15.0 \%$ 的人口通勤距离 在 $1.5 \mathrm{~km}$ 之内。相较于以往北京流动人口通勤距 离研究, 此次研究群体通勤距离相对较短, 主要因 其群体特殊性决定。首先, 城中村流动人口为城市 弱势群体, 调研结果表明, 其月收人多在 2000 6000 元之间, 低于北京人均工资水平, 相对短距离的通 勤可以节约其生活成本。其次, 研究群体居住的城 中村大多在城市边缘区, 其周围就有大量劳动密集 型产业, 就业大部分在外围就业次中心解决(工业 园区等), 职住距离相对缩短。另外, 从通勤方式 看, 本次调研的城中村流动人口出行以自行车/电动 车及公交车为主。其中, 自行车/电动车占比为 $41.6 \%$, 公交车占比 $37.3 \%$ 。相对于长距离的私家 车/出租车、地铁出行方式而言, 研究群体使用短距 离出行方式比例较高, 从而也反映出群体总体通勤 距离较短的特征。

从城中村区位来看, 不同城中村其流动人口有 不一样的通勤距离。三四环间的城中村, 由于毗邻 城市商业核心区, 这部分流动人口需从居住地往城 市核心区工作,其通勤距离普遍在 $4 \mathrm{~km}$ 左右,如吕 家营村、分钟寺、十里河桥等地。在四五环间的城 中村,由于城市部分劳动密集型产业仍有分布在四 环附近, 可满足流动群体的就业需求, 其流动人口 通勤距离主要为 $3 \sim 4 \mathrm{~km}$, 如西手村、廖公庄村、南 桥、横街子、石各庄、黑桥等地。五环附近城中村流

表 2 各城中村流动人口职住距离

Tab.2 Job to housing distance of the surveyed urban village floating population

\begin{tabular}{lccl}
\hline 采样点 & 平均距离/m & 平均时间/min & 所处位置 \\
\hline 沙河 & 12053 & 52.9 & 六环外 \\
南小街 & 1195 & 36.9 & 南四五环间 \\
房村 & 915 & 37.2 & 南五六环间 \\
西由村 & 3074 & 45.5 & 西四五环间 \\
分钟寺 & 4490 & 43.1 & 南三四环间 \\
廖公庄 & 4211 & 48.3 & 西四五环间 \\
南桥 & 4742 & 47.2 & 南四环 \\
横街子 & 3373 & 40.0 & 东四五环间 \\
孛罗营 & 1492 & 37.8 & 东五环西侧 \\
石各庄 & 4138 & 46.7 & 东五环东侧 \\
黑桥 & 4326 & 43.9 & 东北五环 \\
十里河 & 3078 & 38.1 & 南三环东路 \\
马驹桥 & 3975 & 33.1 & 南六环 \\
吕家营 & 4064 & 41.8 & 南四环 \\
\hline
\end{tabular}


动人口通勤距离则相对更短, 这些城中村周边分布 较多的劳动密集型制造业或者居民服务业(服装制 造、汽修等), 通勤距离一般为 1 2 km, 如南小街、房 村、孛罗营等地。而五环以外的城市远郊区城中村 流动人口通勤距离差异较大, 如沙河的平均通勤距 离最长, 该地区流动人口工作集中分布在昌平区驻 地和北京市区, 居住地以其廉价的房租吸引流动人 口, 即这部分流动人口以通勤距离换取生活成本的 降低。马驹桥地区城中村流动人口通勤距离在 4 $\mathrm{km}$ 左右, 通勤距离接近郊型城中村。总体而言, 不 同城中村流动人口通勤距离差异较大, 通勤距离大 致出现近市中心核心区向外围地区递减趋势。

(3) 不同城中村职住分离程度不同, 但大致可 分为 3 类: 职住分离明显、职住分离适宜和职住较为 一体。依托 ArcGIS 提取城中村流动人口居住地与 就业地信息, 得到样本通勤空间格局(图 3)。从城中 村流动人口通勤格局看, 所调研的 14 个城中村都出 现不同程度的职住分离现象。其中, 黑桥地区、南 桥地区、石各庄、廖公庄村等城中村流动人口主要 在四环内就业, 居住在四五环间, 职住分离明显, 这 些城中村流动人口通勤距离大多数在 $4 \mathrm{~km}$ 以上; 分 钟寺、西再村、十里河村、横街子、马驹桥地区及吕 家营村等流动人口工作地职住分离适宜, 但这些城

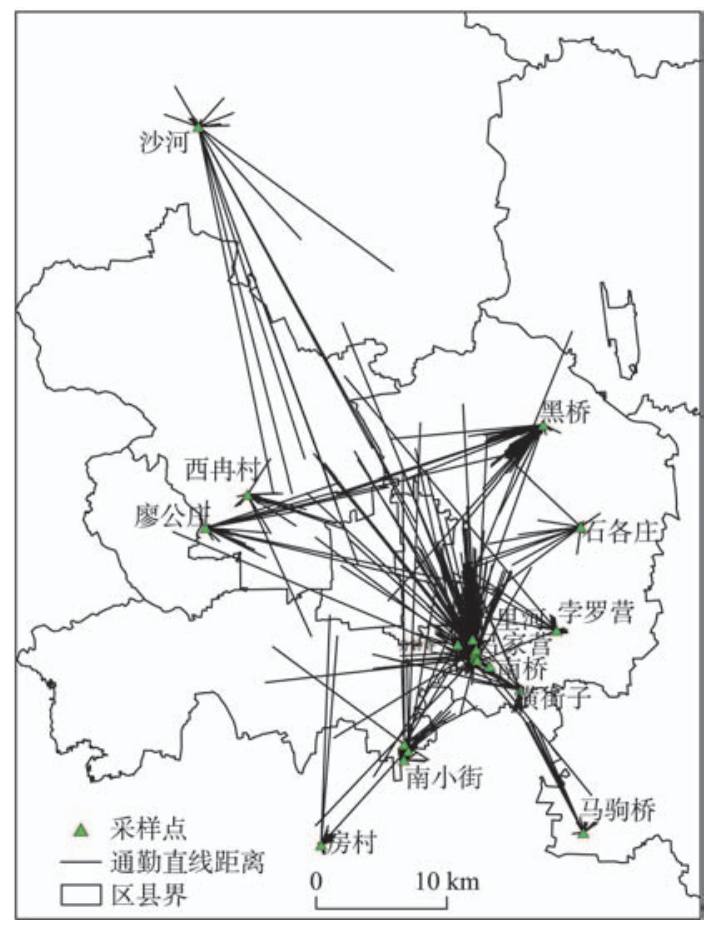

图 3 样本流动人口通勤空间格局

Fig.3 Spatial pattern of commuting of the surveyed urban village floating population
中村有部分流动人口职住较为一体, 这与村中自身 产业带动有关。而远郊地区城中村, 孛罗营、南小 街以及房村流动人口通勤距离较短, 大多数为 $1 \sim$ $1.5 \mathrm{~km}$, 通勤时间都在 $40 \mathrm{~min}$ 内, 表明远郊城中村 自身可提供大量的就业机会, 职住一体较为明显。

由以上特征分析可知; 职住错位现象在不同人 群中都存在,而北京市城中村主要以中低收人流动 人口为主, 由于就业居住机会的制约,往往居住在 远离城市核心区的城市郊区内。近郊区流动人口 就业机会大多来源于城市核心区,使得这部分城中 村流动人口面临长距离、长时间的通勤状况, 其非 工作时间很大一部分都花费在通勤上, 影响到日常 生活质量; 远郊地区, 由于城市劳动密集型企业迁 出城市核心区, 在这些地区落脚以满足流动人口就 业, 相应地这部分城中村流动人口通勤压力较小, 但由于远离城市核心区,一定程度上限制了他们的 空间移动范围, 影响其购物、学习以及公共服务设 施的可达性。但不管哪种通勤职住形式, 客观上都 降低了城中村流动人口的生活质量。

\section{3 通勤距离影响因素}

运用Logit 回归模型, 以城中村流动人口的通 勤距离为因变量, 以受访者经济社会特征信息及城 中村环境为自变量, 对城中村流动人口通勤时间的 影响因素进行探索。结果显示(表 3), 城中村流动人 口家庭未成年人及老年人数、来京时长、月收人、文 化程度、工作行业以及交通工具是影响通勤距离的 显著因素 $(P<0.05)$, 而年龄、户籍、性别、婚姻以及城 中村环境对流动人口通勤距离的影响不显著。

(1) 家庭就业人数、未成年人和老年人数都对 因变量有显著影响。家庭就业人数与通勤距离呈 正相关, 即城中村流动人口家庭就业人数增加, 被 访者的通勤距离变大, 调研数据也表明家庭就业人 数超过 3 个人, 其通勤距离达到 $4.6 \mathrm{~km}$ 左右, 为最大 值。另外, 城中村流动人口的通勤距离是未成人及 老年人人数的减函数, 即随着家庭小孩老人数增 加, 通勤距离一般越短, 这主要与城中村流动人口 的乡土观念有关,一般迁移到大城市的未成年人或 者老人, 由于缺少本地的人际关系, 他们活动范围 普遍较小, 亟需得到家庭其他成员的关心照顾。因 此, 调研对象往往在择业心理上选择离家较近的地 方, 这样可以缩短通勤时间来照顾家中的小孩和 老人。

(2) 来京时间对城中村流动人口通勤距离影响 
表 3 受访流动工人口经济社会特征及城中村环境对通勤距离的影响回归分析

Tab.3 Influence of socioeconomic factors and urban village environment on commuting distance of the surveyed floating population

\begin{tabular}{|c|c|c|c|c|}
\hline \multirow{2}{*}{ 变量名 } & \multirow{2}{*}{ 选项 } & \multicolumn{3}{|c|}{ Logit模型检验结果 $(N=625)$} \\
\hline & & 估计值 & Wald 检验 & 显著性 \\
\hline \multicolumn{2}{|l|}{ 家庭就业人数 } & +0.203 & 4.875 & 0.027 \\
\hline \multicolumn{2}{|l|}{ 家庭未成年人及老人人数 } & -0.203 & 5.135 & 0.023 \\
\hline \multirow[t]{6}{*}{ 来京时间/年 } & $\leqslant 1$ & -0.656 & 10.224 & 0.001 \\
\hline & 2 & -0.517 & 7.155 & 0.007 \\
\hline & 3 & -0.509 & 8.702 & 0.003 \\
\hline & {$[4 \sim 5]$} & -0.583 & 12.633 & 0.000 \\
\hline & $(5 \sim 10]$ & -0.459 & 8.522 & 0.004 \\
\hline & $>10$ & $0.000^{*}$ & & \\
\hline \multirow[t]{5}{*}{ 文化程度 } & 小学及以下 & -1.474 & 5.388 & 0.020 \\
\hline & 初中 & -1.117 & 3.403 & 0.065 \\
\hline & 高中 & -1.091 & 3.270 & 0.071 \\
\hline & 大学专科/本科 & -0.740 & 1.530 & 0.216 \\
\hline & 硕士及以上 & $0.000^{*}$ & & \\
\hline \multirow[t]{5}{*}{ 月收人/元 } & $\leqslant 2000$ & -0.002 & 0.000 & 0.994 \\
\hline & (2000 4000] & -0.328 & 3.758 & 0.053 \\
\hline & (4000 6000] & -0.191 & 1.429 & 0.232 \\
\hline & (6000 8000] & -0.372 & 4.070 & 0.044 \\
\hline & $>8000$ & $0.000^{*}$ & & \\
\hline \multirow[t]{6}{*}{ 工作行业 } & 批发零售业 & +0.092 & 0.517 & 0.472 \\
\hline & 住宿餐饮业 & -0.028 & 0.040 & 0.841 \\
\hline & 交通运输业 & +0.385 & 4.357 & 0.037 \\
\hline & 居民服务业 & +0.241 & 3.393 & 0.065 \\
\hline & 信息传输、计算机服务业和软件业 & +0.380 & 6.156 & 0.013 \\
\hline & 其他 & $0.000^{*}$ & & \\
\hline \multirow[t]{3}{*}{ 交通方式 } & 步行/自行车/电动车 & -0.697 & 15.946 & 0.000 \\
\hline & 公交车/地铁 & +0.042 & 0.177 & 0.813 \\
\hline & 私家车/出租车 & $0.000^{*}$ & & \\
\hline
\end{tabular}

注:*表示由于该参数为圥余, 故将其设置为 0 。

较为显著。以来京时间超过 10 年的流动人口为参 照组, 随着来京时间变长, 城中村流动人口通勤距 离在减小。来京时长越短的城中村流动人口对北 京的熟悉度较低, 由于就业信息获取的局限, 他们 错失较近就业机会较大。而来京时间较久的,由于 当地人际关系的建立, 就业居住信息的丰富, 他们 往往会选择通勤距离较短的工作, 这样利于其生活 质量的提高。

(3) 文化程度对城中村流动人口通勤距离影响 系数为负, 且估计系数呈递减趋势, 说明学历越高 对通勤距离的限制作用越弱。以硕士及以上学历 为参照组, 其中小学及以下对因变量影响最为显 著, 这部分流动人口通勤距离远低于均值。由于受
教育水平较低所限,这部分流动人口在城市中只能 提供低端服务, 例如菜市场工作、街头小贩等, 为城 中村提供居民服务等, 其通勤距离也相应较短。

(4) 收人水平对城中村流动人口通勤距离影响 系数为负, 以收人>8000 元为参照组, 收人 6000 8000 元高收人对因变量影响最为显著。低收人群 体( $\leqslant 2000$ 元)的通勤距离较大, 与该群体以收废品、 住宿与餐饮服务人员、批发与零售人员为主有关。 中等收人群体(2000 4000 元) 的平均通勤距离较 小, 与这部分人群中以产业工人和汽修工人为主有 关,居住则由紧邻园区城中村提供。高收人群体的 通勤距离最长, 与高收人群体多使用私家车或者乘 坐出租车及地铁有关。 
(5) 城中村流动人口从事行业对通勤距离影响 显著。相对于其他行业, 交通运输业与信息传输、 计算机服务业和软件业对因变量的影响更为显著, 从事这 2 个行业的人数分别为 40 人与 71 人, 分别占 城中村流动人口总数的 $6.40 \%$ 与 $11.36 \%$ 。从事交 通运输业的城中村流动人口通勤距离高于均值, 这 与其工作地主要在四环内有关。信息传输、计算机 服务业和软件业具有最大的通勤距离和通勤时间， 主要与这部分流动人口收人、受教育程度较高, 其 移动范围受限较小, 加之这部分流动人口就业地集 中分布城市核心区而居住则在城郊有关。

(6) 交通方式对于城中村流动人口通勤距离的 影响, 以私家车/出租车为参照组, 步行、自行车和电 动车对通勤距离影响显著且影响系数为负, 说明相 较于其他交通方式, 采用步行、自行车和电动车方 式出行的城中村流动人口通勤距离较小。

\section{4 结论与讨论}

本文从北京城中村流动人口角度出发, 通过问 卷和走访调查获得其社会经济和通勤行为等数 据。在此基础上探讨其职住分离程度以及通勤距 离影响因素, 为进一步理解北京城中村流动人口工 作生活空间提供参考。

\section{1 结论}

(1) 从北京流动人口空间分布上看, 其主要集 中于城市拓展区, 且呈 “环状圈层” 分布特征, 这也 反映出流动人口随着北京市住宅郊区化发展向远 离城市核心区的地区聚居生活。

(2) 由于不同城中村在空间结构、交通条件等 方面差异, 城中村流动人口社会经济属性特征也不 同, 同时出现不同程度的职住空间错位。近郊城中 村流动人口存在职住不匹配, 面临长距离, 长时间 的通勤困境; 远郊城中村流动人口通勤压力相对较 小, 职住匹配较好, 但远离城市核心区限制了这部 分流动人口的空间移动范围, 相应制约了其购物、 学习以及公共服务设施的可达性。

(3) 通过 Logit 回归分析, 城中村流动人口家庭 就业人数、未成年人及老人数、来京时长、月收人、 文化程度、工作行业、交通工具等因素影响其通勤 距离。其中, 未成年人及老年人数、来京时长, 工作 行业对通勤距离差异影响最为显著。各具体因素 对城中村流动人口通勤距离的影响也存在较大
差异。

\section{2 讨论}

当前, 城中村流动人口居住一就业匹配程度不 同, 无论近郊长距离通勤, 还是远郊职住匹配较好 都反映了城市低收人群体择业难、职业培训缺乏、 公共服务配套不够完善等社会问题。同时,随着北 京市产业升级和非首都职能疏解, 城中村流动人口 的通勤格局可能趋向复杂, 而如何关爱城中村该群 体生活是未来政府部门和社会需要认真考虑的重 要方面。为此, 在 “以人为本”思想指导及城中村特 殊的城市居住形态下, 政府在治理改善城中村环境 的同时,应通过增加公共交通设施、公共服务设施、 住房以及规划政策等,解决城中村流动人口在居 住、就业和通勤选择上可能出现的限制, 增加他们 在城市的认同度和幸福感,这有利于社会的长治 久安。

本文不足之处是城中村流动人口通勤距离采 用职住的直线距离, 缺乏真实情况模拟,未来希望 通过个体实时定位技术来测算实际通勤轨迹。另 外, 未对城中村流动人口就业方向与北京市整体产 业布局关系进行梳理, 流动人口居住与城中村关系 如何也未分析, 这些都关系到城中村流动人口的切 身利益,也是未来进一步研究的重点。

\section{参考文献(References)}

党云晓, 董冠鹏, 余建辉, 等. 2015. 北京土地利用混合度对

居民职住分离的影响 [J]. 地理学报, 70(6): 919-930.

[Dang Y X, Dong G P, Yu J H, et al. 2015. Impact of landuse mixed degree on resident's home- work separation in Beijing[J]. Acta Geographica Sinica, 70(6): 919-930.]

贾晓朋, 孟斌, 张媛媛. 2015. 北京市不同社区居民通勤行为 分析 [J]. 地域研究与开发, 34(1): 55-59. [Jia X P, Meng B, Zhang Y Y. 2015. Analysis of the residents commuting behavior in different communities in Beijing City[J]. Areal Research and Development, 34(1): 55-59.]

兰宗敏, 冯健. 2010. 城中村流动人口的时间利用以及生活 活动时空间结构: 对北京 5 个城中村的调查 [J]. 地理研 究, 29(6): 1092-1104. [Lan Z M, Feng J. 2010. The time allocation and spatio-temporal structure of the activities of migrants in 'village in city': Surveys in five 'villages in city' in Beijing[J]. Geographical Research, 29(6): 10921104.]

兰宗敏, 冯健. 2012. 城中村流动人口日常活动时空间结构: 基于北京若干典型城中村的调查 [J]. 地理科学, 32(4): 409-417. [Lan Z M, Feng J. 2012. The spatio-temporal 
structure of migrant's daily activities of village in city: Case of typical villages in city of Beijing, China[J]. Scientia Geographica Sinica, 32(4): 409-417.]

李晴, 常青. 2002. “城中村”改造实验: 以珠海吉大村为例 [J]. 城市规划, 26(11): 23-27, 45. [Li Q, Chang Q. 2002. Experiment for the renovation of "city village": Jida Village in Zhuhai City as the example[J]. City Planning Review, 26(11): 23-27, 45.]

李小广, 邱道持, 李风, 等. 2013. 重庆市公共租赁住房社区 居民的职住空间匹配 [J]. 地理研究, 32(8): 1457-1466. [Li X G, Qiu D C, Li F, et al. 2013. Matching analysis of the job and residence space of residents in the public rental housing community in Chongqing[J]. Geographical Research, 32(8): 1457-1466.]

李到. 2001. “城中村” 改造途径的思考 [J]. 安徽建筑, 8(3): 89. [Li Z. 2001. "Chengzhongcun" gaizao tujing de sikao [J]. Anhui Architecture, 8(3): 8-9.]

刘志林, 王茂军. 2011. 北京市职住空间错位对居民通勤行 为的影响分析: 基于就业可达性与通勤时间的讨论 [J]. 地理学报, 66(4): 457-467. [Liu Z L, Wang M J. 2011. Job accessibility and its impacts on commuting time of urban residents in Beijing: From a spatial mismatch perspective [J]. Acta Geographica Sinica, 66(4): 457-467.]

刘志林, 王茂军, 柴彦威. 2010. 空间错位理论研究进展与方 法论评述 $[\mathrm{J}$ ]. 人文地理, 25(1): 1-6. [Liu Z L, Wang M J, Chai Y W. 2010. Spatial mismatch theory: A review on empirical research and methodology[J]. Human Geography, 25(1): 1-6.]

卢小君, 陈慧敏. 2012. 流动人口社会融合现状与测度: 基于 大连市的调查数据 [J]. 城市问题, (9): 69-73. [Lu X J, Chen H M. 2012. Current status and measurement of social integration of migrants: The case of Dalian City[J]. Urban Problems, (9): 69-73.]

罗仁朝, 王德. 2008. 基于聚集指数测度的上海市流动人口 分布特征分析 [J]. 城市规划学刊, (4): 81-86. [Luo R C, Wang D. 2008. An analysis on characteristics of floating population distribution in Shanghai by means of accumulation index[J]. Urban Planning Forum, (4): 81-86.]

孟斌, 于慧丽, 郑丽敏. 2012. 北京大型居住区居民通勤行为 对比研究: 以望京居住区和天通苑居住区为例 $[\mathrm{J}]$. 地理 研究, 31(11): 2069-2079. [Meng B, Yu H L, Zheng L M. 2012. The analysis of commuting behavior in the huge residential districts: A case study of Wangjing and Tiantongyuan in Beijing[J]. Geographical Research, 31(11): 20692079.]

宋金平, 王恩儒, 张文新, 等. 2007. 北京住宅郊区化与就业 空间错位 [J]. 地理学报, 62(4): 387-396. [Song J P, Wang E R, Zhang W X, et al. 2007. Housing suburbanization and employment spatial mismatch in Beijing $[\mathrm{J}]$. Acta Geo- graphica Sinica, 62(4): 387-396.]

孙斌栋, 但波. 2015. 上海城市建成环境对居民通勤方式选 择的影响 [J]. 地理学报, 70(10): 1664-1674. [Sun B D,

Dan B. 2015. Impact of urban built environment on residential choice of commuting mode in Shanghai[J]. Acta Geographica Sinica, 70(10): 1664-1674.]

孙斌栋, 潘金金, 宁越敏. 2008. 上海市就业与居住空间均衡对 交通出行的影响分析[J]. 城市规划学刊, (1): 77-82. [Sun B D, Pan X, Ning Y M. 2008. Analysis on influence of jobhousing balance on commute travel in Shanghai[J]. Urban Planning Forum, (1): 77-82.]

陶海燕, 周淑丽, 卓莉. 2014. 城中村有序改造的群决策: 以 广州市城中村改造为例 [J]. 地理研究, 33(7): 1207-1216. [Tao H Y, Zhou S L, Zhuo L. 2014. Group decision-making on well- order renovation of urban villages: A case study of Guangzhou[J]. Geographical Research, 33(7): 1207-1216.]

汪明峰, 程红, 宁越敏. 2015. 上海城中村外来人口的社会融 合及其影响因素 $[\mathrm{J}$ ]. 地理学报, 70(8): 1243-1255. [Wang M F, Cheng H, Ning Y M. 2015. Social integration of migrants in Shanghai's urban villages[J]. Acta Geographica Sinica, 70(8): 1243-1255.]

王宁, 王录仓, 李纯斌, 等. 2009. 基于 “空间失配”假设的居 民就业障碍研究: 以兰州市城关区城中村为例 [J]. 经济 地理, 29(4): 650-653. [Wang N, Wang L C, Li C B, et al. 2009. Study on employment obstacles of the residents based on "spatial mismatch": Taking city village in Chengguan District of Lanzhou City as the example[J]. Economic Geography, 29(4): 650-653.]

徐市融, 吴晓. 2010. 基于 “居住一就业”视角的南京市流动 人口职住空间分离量化 [J]. 城市规划学刊, (5): 87-97.

[Xu B R, Wu X. 2010. Quantitative analysis of the separation of residential and employment space of the floating population in Nanjing[J]. Urban Planning Forum, (5): 87-97.]

杨菊华, 张莹, 陈志光. 2013. 北京市流动人口身份认同研 究: 基于不同代际、户籍及地区的比较 $[\mathrm{J}]$. 人口与经济, (3): 43-52. [Yang J H, Zhang Y, Chen Z G. 2013. Migrants' identificational assimilation in Beijing: A comparative study based on generation, hukou and area[J]. Population \& Economics, (3): 43-52.]

英成龙, 雷军, 段祖亮, 等. 2016. 乌鲁木齐市职住空间组织 特征及影响因素 [J]. 地理科学进展, 35(4): 462-475. [Ying C L, Lei J, Duan Z L, et al. 2016. Characteristics of jobs-housing spatial organization in Urumqi City and influencing factors[J]. Progress in Geography, 35(4): 462-475.] 余运江, 高向东, 郭庆. 2012. 新生代乡一城流动人口社会融 合研究: 基于上海的调查分析 [J]. 人口与经济, (1): 5764. [Yu Y J, Gao X D, Guo Q. 2012. Research on social in- 
tegration for new generation of rural- urban migrants: Based on the survey in Shanghai[J]. Population \& Economics, (1): 57-64.]

张京祥, 赵伟. 2007. 二元规制环境中城中村发展及其意义 的分析 [J]. 城市规划, 31(1): 63-67. [Zhang J X, Zhao W. 2007. City village in dual-system environment: Development and significance[J]. City Planning Review, 31(1): 6367.]

张艳, 柴彦威. 2013. 生活活动空间的郊区化研究 [J]. 地理科 学进展, 32(12): 1723-1731. [Zhang Y, Chai Y W. 2013. Study on suburbanization of living and activity space[J]. Progress in Geography, 32(12): 1723-1731.]

周素红, 间小培. 2006. 基于居民通勤行为分析的城市空间 解读: 以广州市典型街区为案例 [J]. 地理学报, 61(2): 179-189. [Zhou S H, Yan X P. 2006. The impact of commuters' travel pattern on urban structure: A case study in some typical communities in Guangzhou[J]. Acta Geographica Sinica, 61(2): 179-189.]

Aguilera A. 2005. Growth in commuting distances in French polycentric metropolitan areas: Paris, Lyon and Marseille [J]. Urban Studies, 42(9): 1537-1547.
Giuliano G. 1991. Is jobs-housing balance a transportation issue[J]. Transportation Research Record, 1305: 305-312.

Horner M W. 2004.Spatial dimensions of urban commuting: A review of major issues and their implications for future geographic research $[\mathrm{J}]$. The Professional Geographer, 56 (2): 160-173

Lee B S, McDonald J F. 2003. Determinants of commuting time and distance for Seoul residents: The impact of family status on the commuting of women[J]. Urban Studies, 40 (7): 1283-1302.

Levine J. 1998. Rethinking accessibility and jobs-housing balance[J]. Journal of the American Planning Association, 64 (2): 133-149

Peng Z R. 1997. The jobs-housing balance and urban commuting[J]. Urban Studies, 34(8): 1215-1235.

Shen Q. 2000. Spatial and social dimensions of commuting[J]. Journal of the American Planning Association, 66(1): 6882.

Sohn J. 2005. Are commuting patterns a good indicator of urban spatial structure[J]. Journal of Transport Geography, 13 (4): 306-317.

\title{
Job-housing mismatch of floating population in urban villages of Beijing
}

\author{
ZHENG Chengzhi', ZHANG Wangfeng ${ }^{1 *}$, WU Bingyan' ${ }^{1}$, LIANG Bo ${ }^{2}$ \\ (1. College of Earth and Environment Sciences, Lanzhou University, Lanzhou 730000, China; \\ 2. Institute of Disaster Reduction and Emergency Management, Beijing Normal University, Beijing 100875, China)
}

\begin{abstract}
Homemaking and work are the most important contents of the daily activities of residents. With the accelerated process of urbanization in China, the separation between jobs and residential location of urban lowincome groups is getting increasingly more attention. Based on the population concentration index, GIS spatial analysis, and Logit regression analysis methods, and using Beijing's sixth census data and the urban village survey data collected in 2015 , we examined the characteristics of the floating population in commuting and the job-housing path, and analyzed the influencing factors. The analysis results show that the distribution of the floating population in Beijing is concentrated in the urban expanded area, and presents a "ring circle" distribution pattern. The floating population of suburban villages usually has a long commuting distance and an obvious separation of workplace and residence, and the corresponding commuting time is long. The floating population of outer suburban villages has a shorter commuting distance and works near their homes, but these places are far away from the urban core area, and accessibility to public service facilities is poor. The number of employed, young, and old members of household, duration of residence in Beijing, income, education level, profession, and means of transportation have significant impacts on commuting distance. The results can provide a reference for understanding the job-housing space structure of the marginalized population in the city and for urban planning.
\end{abstract}

Key words: commuting; floating population; job-housing mismatch; urban village; Beijing 